\title{
Study of Clamping System Plasticity FOR REAMING TOOLS
}

\author{
Michal Povolny, Jaroslava Fulemova, Jan Rehor \& Tomas Zatloukal
}
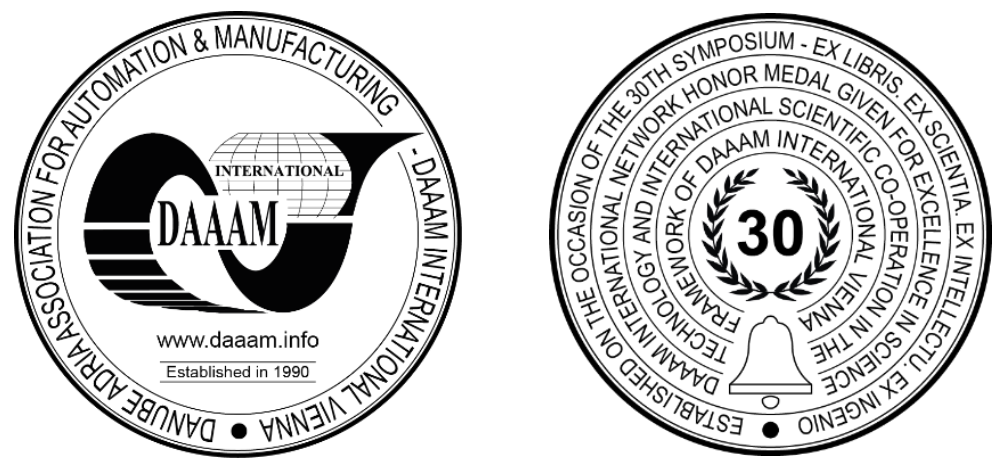

This Publication has to be referred as: Povolny, M[ichal]; Fulemova, J[aroslava]; Rehor, J[an] \& Zatloukal, T[omas] (2019). Study of Clamping System Plasticity for Reaming Tools, Proceedings of the 30th DAAAM International Symposium, pp.1041-1048, B. Katalinic (Ed.), Published by DAAAM International, ISBN 978-3-902734-22-8, ISSN 1726-9679, Vienna, Austria

DOI: $10.2507 / 30$ th.daaam.proceedings. 145

\begin{abstract}
Reaming is finishing technology and its main purpose is to obtain required dimension of the hole and also to improve quality of machined surface, geometric deviations of shape and position. This article deals with problem of tools centering for manufacturing of precise holes by reaming. The goal of this article is verification of new tool system design with defined rigidity, resp. flexibility of clamped tool due to element, which joins tool with a machine tool. The tool system behaviour under the certain type of load is done by FEM analysis. For these analyses are used computing systems Autodesk Nastran In-CAD and Siemens NX 11.0. FEM analyses are verified on the real tool prototypes.
\end{abstract}

Keywords: Reaming; Tool holder; Centering; Floating holder; FEM; Eccentricity; Stress

\section{Introduction}

The main purpose of reaming is improving the quality of the machined surface, geometric divergence of shape and position and obtain the required dimension of the holes. These holes are pre-machined by drilling, milling, casting or the other methods. Accuracy of dimensions produced by reaming is IT6 - IT8 and surface roughness Ra $0.3-0.8 \mu \mathrm{m}$ and they are achieved as standard. Parameters that are most affected by reaming include surface roughness Ra and geometric shape tolerances, namely roundness and cylindricity. These parameters are influenced by the machine tool selection, the cutting conditions and the tool and its clamping. Other parameters that are also important for the hole, such as parallelism, perpendicularity and alignment, are minimally affected by reaming. Their resulting value is mainly determined by operations that are realized before reaming, such as drilling. [1] [2]

An important parameter for reaming is to ensure the stability of the cutting process and thereby minimize chatter or vibration. The stability of the cutting process can affect resulting roundness and cylindrical values. The basic requirement is the overall rigidity of the machine-tool system. Another requirement is the lowest radial runout value of the clamped tool, which is most affected by the tool clamping system (how exactly it can clamp the tool). Next parameter affecting the final accuracy of the reamed hole is the accuracy positioning of the machine tool, i.e. the position of the cutting tool relative to the workpiece. It is therefore the cumulative effects of inaccuracies of the machine - tool system. [3] [4] 
This paper is focused only on aspects which can affect the resulting reamed hole in terms of the position of the tool to the reamed hole and its rigidity and flexibility. The main aim of the paper is to verify the behaviour of tool systems loaded by static force and defined by offset value using FEM analysis. Autodesk Nastran In-CAD and Siemens NX 11.0 software will use for these analysis. Partial aims of the work is to create CAD models of the tool holder system with variable tool overhang, and FEM analysis of tool systems depending on their misalignment or force load. Verification of the results of FEM analysis will be done on the real prototype of tool holder. Then will be compare the results of FEM analysis with the measured data. And final evaluation of achieved results and technical and economic evaluation.

\section{Cutting tool centering systems}

The tool-holder system can be evaluated from many different perspectives. However, from the point of view of the centring of the cutting tool should achieve the highest accuracy, the lowest roundness and cylindricality. In terms of tool centering, the tool holder can be divided into active and passive systems. Passive systems have a clearly defined tool clamping accuracy based on the holder design. Clamping system producers typically refer to clamping accuracy as the maximum circumferential runout of the tool. Therefore, passive systems centre the tool, but only to a certain value that can no longer be influenced. These tool centering systems include "Weldon" holder, collet chucks, hydraulic, thermal and force deformation chucks. The maximum runout size is often in the order of micrometres. However, this runout is usually measured at a distance of 2.5 D from the face of the chuck and not at the cutting edge of the tool. As the tool length increases, the radial runout value of the cutting tool increases accordingly. Active tool centering systems are based on passive systems, but they add the ability to adjust the degree of eccentricity (runout) up to micrometres in the area of the cutting edges or the tool tip for almost any length of overhang. Very frequent function of the active tool centring systems is to control the eccentricity of the clamped tool. This is most often solved by adding an alignment part, on the perimeter of which are located adjusting screws to adjust the radial runout. Another possible function is to compensate axial and angular displacement of the tool axis relative to the hole axis, or to compensate for deviations and tool fault. For this purpose, the so-called floating tool clamping principle or self-centering holders are used. The floating holder is mainly used where there is a misalignment between the cutting tool and the machine spindle. Especially in reaming operations where the reamer should follow a pre-drilled hole and should not be influenced by the spindle position. The floating holder then maintains the alignment of the reamer with the pre-drilled hole so as to prevent the formation of oval, bellshaped and conical holes. [2] [5] [6]

\section{Self-centering reaming holder}

The following is a tool system based on the principle of active tool centering in the production of precision holes by reaming. This is the initial design of a tool prototype for self-centred reaming consisting of clamping and machining parts, see in Fig. 1. The cutting part is connected to the clamping part by means of a torsionally and buckling-rigid, yet radially flexible coupling part. The holder operates on the principle of a radially pliable clutch part and therefore allows automatic centering of the tool in case of misalignment of the pre-drilled hole and the axis of the cutting tool. The tool designed in this way is particularly suitable as a stationary tool, i.e. where the rotary movement is performed by the workpiece (used for example on lathes). Based on the initial design of the self-centering holder prototype, other technical variants are based on self-centering holders. As already mentioned, the imperfect alignment of the pre-drilled hole and the cutting tool results in a deterioration in the manufacturing accuracy and also in a faster destruction of the tool. Similar problems are caused by misalignment of the cutting part of the tool with its axis of rotation. A significant disadvantage of using reamers with extended shank is its bending when the cutting part of the tool enters the pre-drilled hole. This results in a deterioration in geometric accuracy and faster tool wear. The above-mentioned drawbacks are eliminated by the technical solution of the self-centering holder, where torsionally and buckling-rigid, yet radially flexible coupling part ensure the correct guiding of the tool into the pre-drilled hole. [7] 


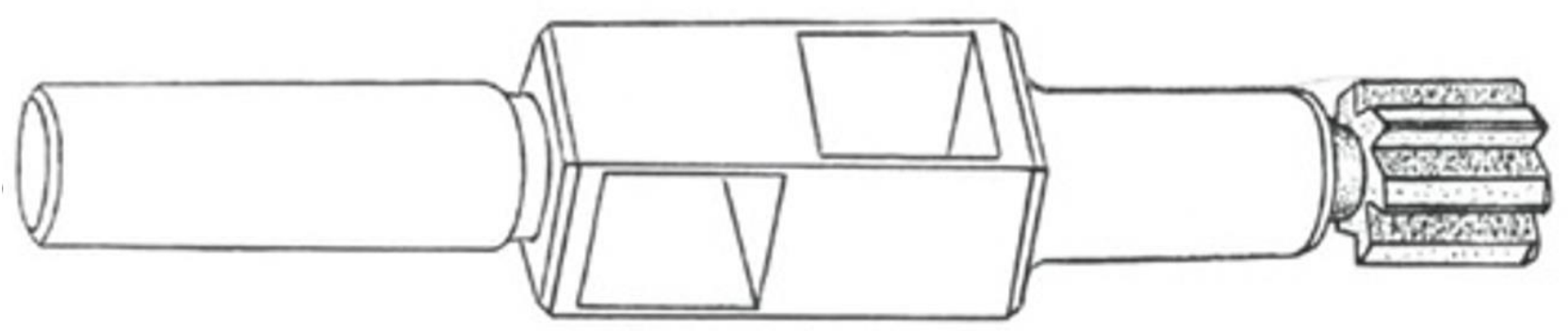

Fig. 1. Prototype of self-centering reaming holder [8]

\section{FEM analysis of clamping system}

The aim of FEM analysis was to verify the behaviour of tool systems and to determine the maximum stresses resulting from the prescribed load or misalignment and subsequent comparison with the maximum permissible value of stress or misalignment. Analyses were performed on a simplified CAD model using Autodesk Nastran in-CAD and Siemens NX 11.0. After that the results were compared with the maximum allowable value. The simulation was performed for two different dimensional variants that are different in the dimensions of the flexible parts, see in Table 1. The simulation was performed to determine the maximum stress at a given tool system offset for six tool holder overhangs from $100 \mathrm{~mm}$ to $130 \mathrm{~mm}$. During simulations, the tool system was deflected by the selected offset and the maximum stresses were determined. This was followed by a simulation to determine the stress at an overhang $125 \mathrm{~mm}$ with variable offset. Verification of the results was performed for one of the options of the self-centering tool holder on a real prototype of this tool.

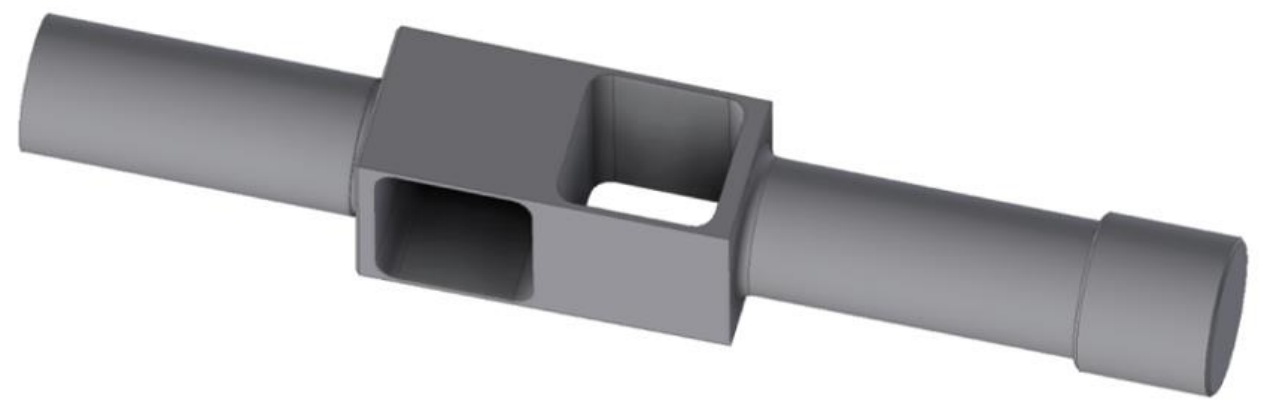

Fig. 2. Simplified CAD model of the tool system

\begin{tabular}{|c|c|c|c|c|c|c|}
\hline & \multicolumn{4}{|c|}{ Dimensions [mm] } & \multirow{2}{*}{$\begin{array}{c}\text { Maximum } \\
\text { permissible } \\
\text { offset } \\
\text { [mm] }\end{array}$} & \multirow{2}{*}{$\begin{array}{c}\text { Maximum } \\
\text { permissible } \\
\text { stress } \\
{[\mathrm{MPa}]}\end{array}$} \\
\hline & $\begin{array}{l}\text { Length of } \\
\text { flexible part }\end{array}$ & $\begin{array}{l}\text { Length of } \\
\text { slats }\end{array}$ & $\begin{array}{c}\text { Thickness } \\
\text { of slats }\end{array}$ & Dimensions & & \\
\hline Option 1 & 55 & 23 & 0.95 & $25 \times 25$ & 0.15 & 280 \\
\hline Option 2 & 57 & 24 & 1.2 & $27 \times 27$ & 0.1 & 203 \\
\hline
\end{tabular}

Table 1. Different parameters of two variants of self-centering tool

\subsection{Maximum stress analysis at tool offset}

The following section is focused on simulations where the tool is offset (from $0.01 \mathrm{~mm}$ to $0.2 \mathrm{~mm}$ ). The aim of the simulations is to determine the maximum stress in the tool holder and to see if the tool can withstand this stress. Or the tool may become permanently deformed or can be destroyed. The simulated offset represents the misalignment of the pre-drilled hole with the tool axis. Fig. 4 shows the distribution of stress for the first option, where $\mathrm{L}=125 \mathrm{~mm}$ and offset $0.002 \mathrm{~mm}$. It is obvious that the maximum stress is concentrated on the inside of the slats, where the radius passes into the slat wall, and at the concurrently in the transition from the end of the radius to the lateral edges of the slat. 


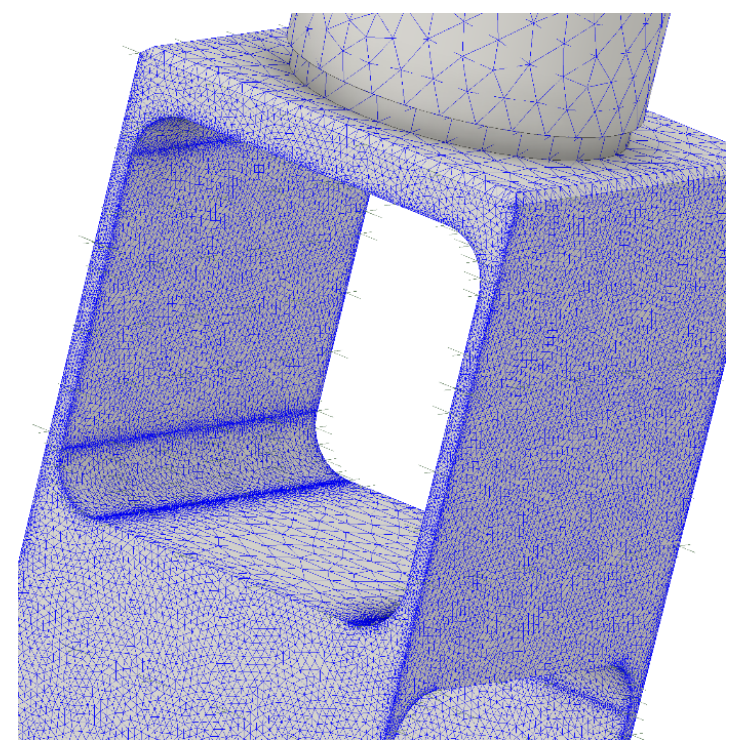

Fig. 3. Mesh model from Autodesk Nastran In-CAD

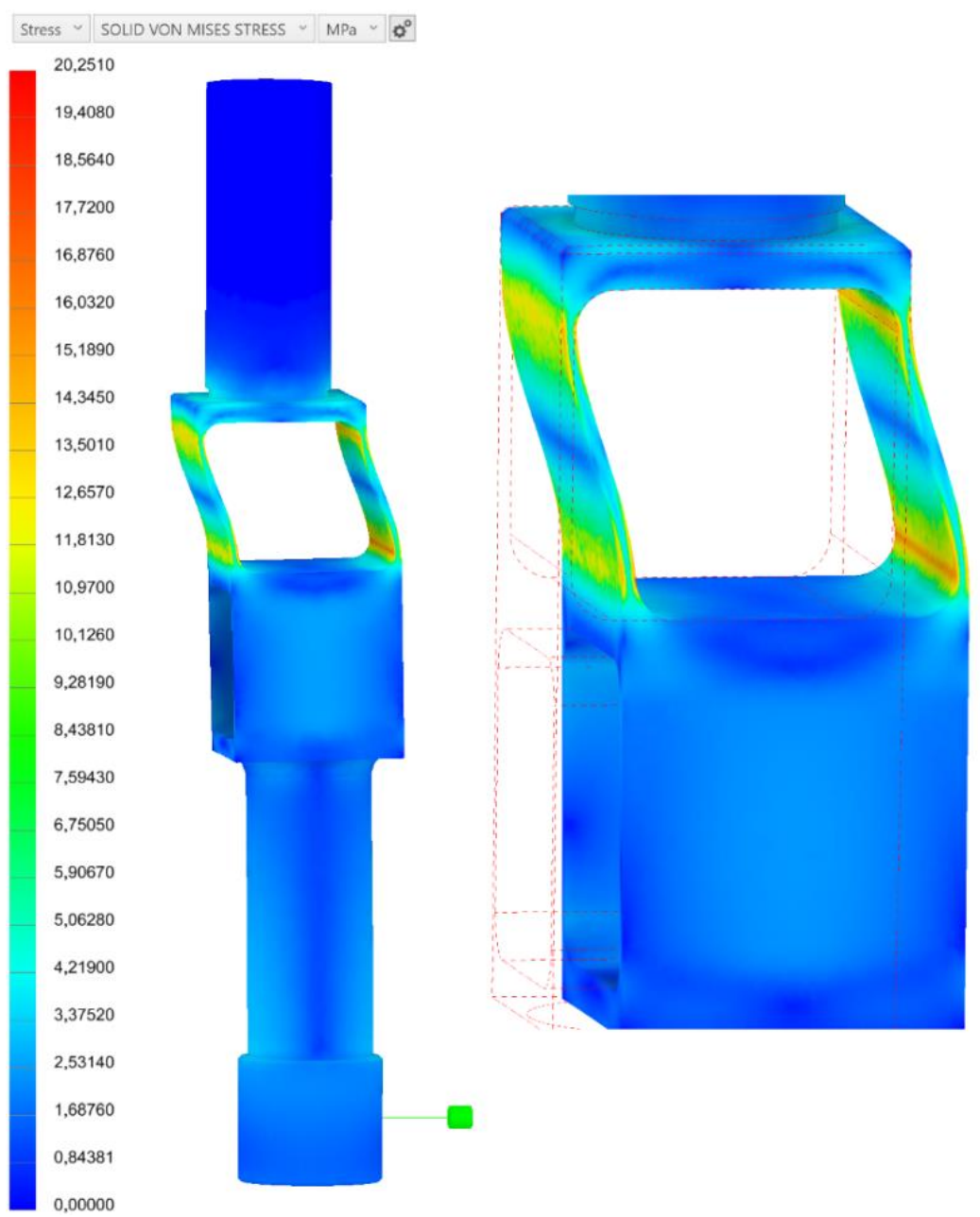

Fig. 4. FEM stress analysis for option $1 \mathrm{~L}=125 \mathrm{~mm}$ and offset $0.002 \mathrm{~mm}$ 


\section{Maximum stress at different offset}

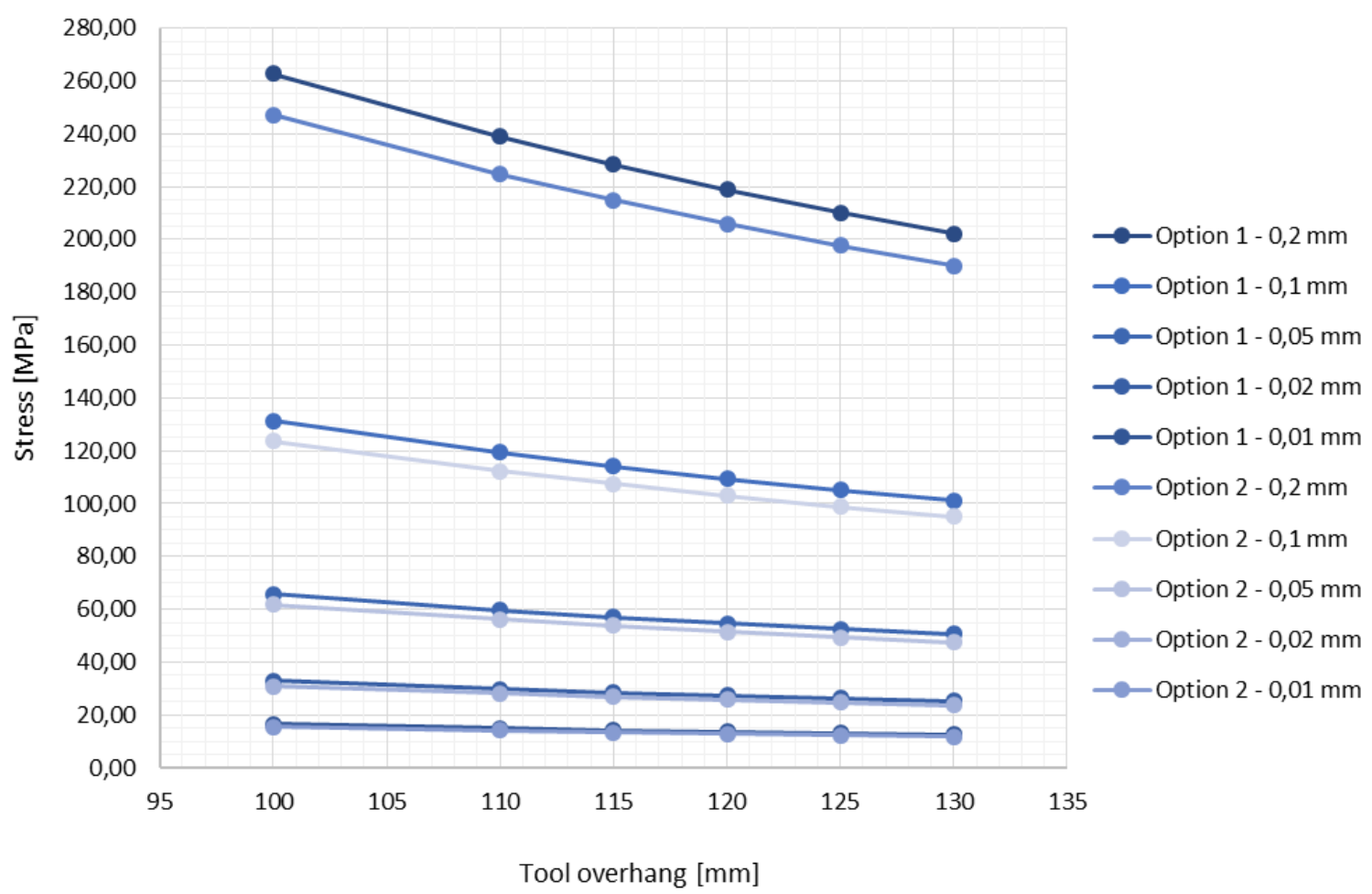

Fig. 5. Dependence of maximum stress on tool overhang at different offset

The graph in Fig. 5 shows the maximum stress for the tool offset of $0.01 \mathrm{~mm}, 0.02 \mathrm{~mm}, 0.05 \mathrm{~mm}, 0.1 \mathrm{~mm}$ and $0.2 \mathrm{~mm}$ for both dimensional options depending on the tool overhang. Simulations were used to determine the maximum stresses generated when offset in a direction perpendicular to the two upper flexible lamellas of the holder. Furthermore, it has been found that the greatest stress occurs at the lowest tool overhang $(\mathrm{L}=100 \mathrm{~mm})$. For an offset of $0.2 \mathrm{~mm}$, the maximum stress value for the option 1 is 1,262 MPa and for the option 2 is 2,247 $\mathrm{MPa}$. An offset of $0.2 \mathrm{~mm}$ or more, there is a risk of permanent deformation of the material and destruction, especially with a smaller tool overhang. It is further evident from the graph that the same offset value will cause an approximately $6.5 \%$ stress increase for option 1 , compared to the more robust option 2

\subsection{Maximum stress analysis for 125 mm overhang at variable offset}

Next FEM analysis was focused only on the $125 \mathrm{~mm}$ tool overhang in both dimensional options. The aim of the simulations was to determine the value of the maximum stress that grow during tool offset, up to $0.2 \mathrm{~mm}$. The following graph (see in Fig. 6) shows the course of the maximum stress depending on the overhang of the tool for both variant. From this graph it is evident that even at maximum tool offset of $0.2 \mathrm{~mm}$ the maximum permissible stress of $280 \mathrm{MPa}$ for option 1 and $230 \mathrm{MPa}$ for option 2 will not be exceeded. The simulation was used to determine the limit of the maximum offset at which this allowable stress is exceeded, which is a value of $0.233 \mathrm{~mm}$ for option 1 and $0.265 \mathrm{~mm}$ for option 2. The graph also shows a relatively small difference in the values of the maximum stresses between the twodimensional options. The more robust option 2 reach an approximately $6.5 \%$ lower maximum stress than option 1 , with almost 20\% less permissible stress than option 1 . 


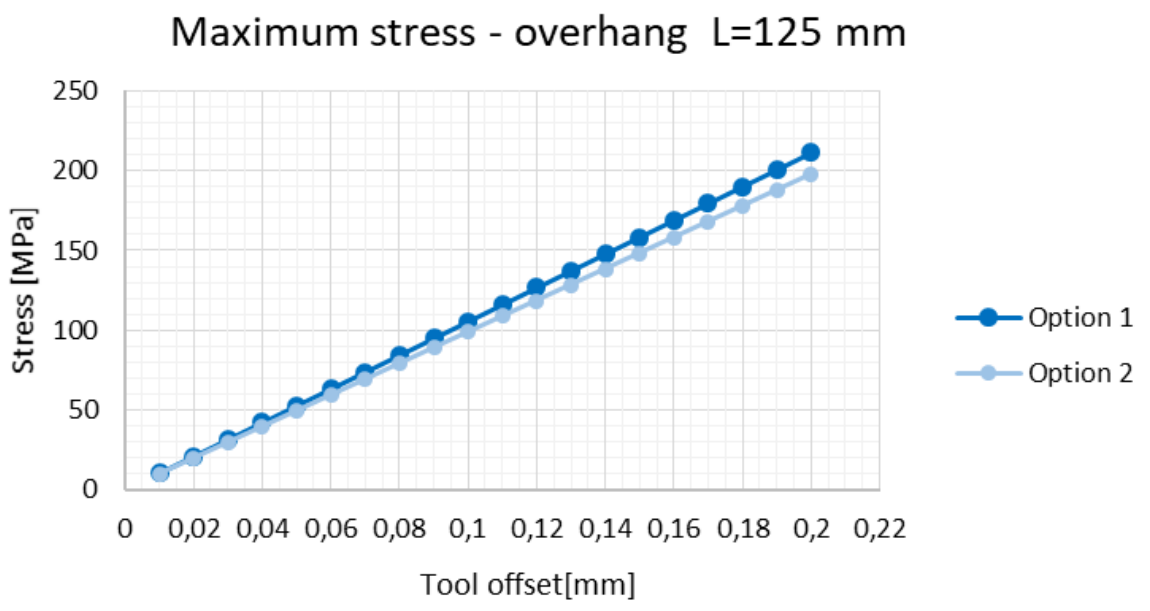

Fig. 6. Dependence of maximum stress on tool offset at overhang $\mathrm{L}=125 \mathrm{~mm}$

\section{Verification of FEM analyses on a real prototype tool}

After performing the simulations and analysis, it was necessary to verify achieved results. It means confirm if they are relevant and can help as input data for further research and experiments. Siemens NX 11.0 was used to verify the simulation results. This was followed by an experiment to verify the FEM model on a real example. Verification was carried on the prototype self-centering holder for option with overhang $\mathrm{L}=125 \mathrm{~mm}$. Due to the difficult measurement of the maximum stress in the tool, it was necessary to evaluate the stresses from the strain gauges located on the tool slats. For the final comparison in the graphs, the stress from the simulations was also measured in the area where the strain gauges were glued. It was not a comparison of the maximum stresses created, but a comparison of the stresses in a particular area under strain gauges. The prepared tool with attached strain gauges was fixed in the machine spindle using a hydraulic clamp. The lower cylindrical part, which simulates the cutting part of the reamer, was "leaning" on the workpiece, which was clamped on the dynamometer. By moving the machine spindle in the x-axis relative to the rotary table with the dynamometer, was achieved the required alignment of the tool axis relative to the axis of the lower cylindrical part. Fig. 7 shows the prepared tool with strain gauges, clamped in the machine tool in the unloaded position and ready for the experiment.

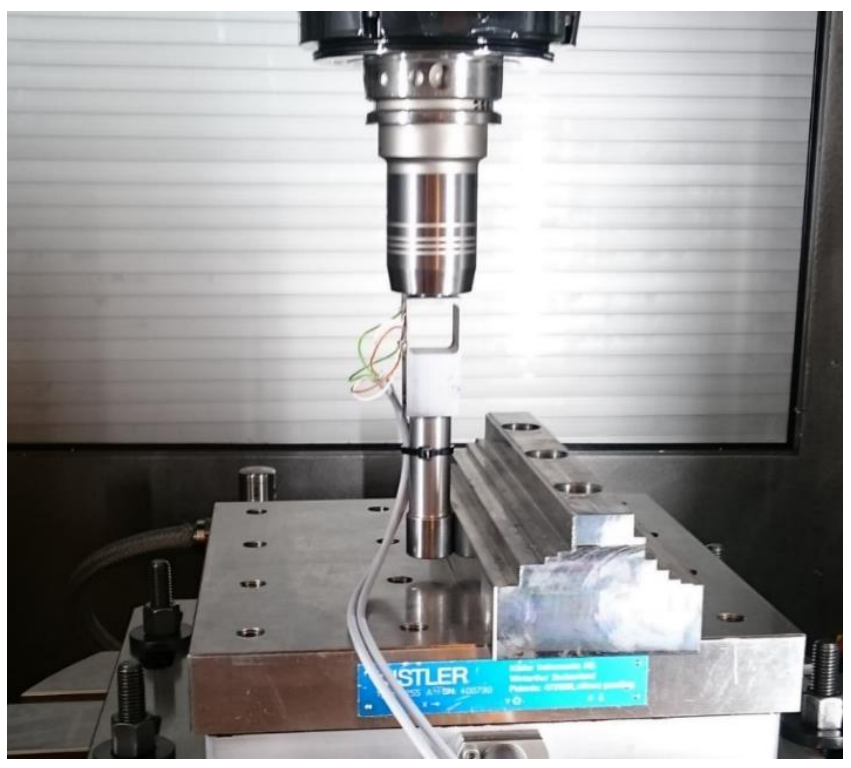

Fig. 7. Experiment on real prototype of self-centering tool 
To evaluate the experiment, it was first necessary to calculate the resulting stress from the values of the relative extension, which was measured by strain gauges. The results from the upper strain gauge showed the compressive stress and the results from the lower strain gauge showed the tensile stress. These results confirmed the simulation data and correspond to the basic principles of elasticity and strength. Next, graphs of stress versus tool offset were constructed, which compare the stresses evaluated from the experiment with the stresses gets from the simulations.

\section{Option 1 - Presure stress}

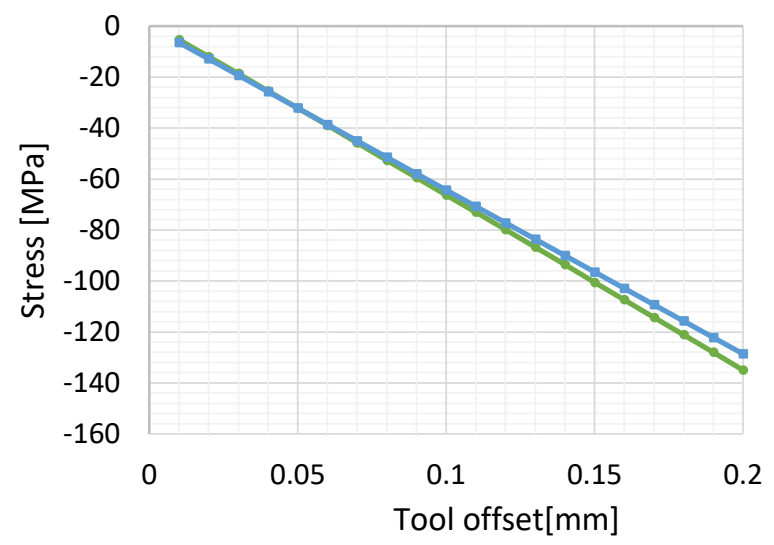

$\longrightarrow$ Experiment
Tool offset[mm]

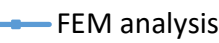

\section{Option 1 - Tensil Stress}

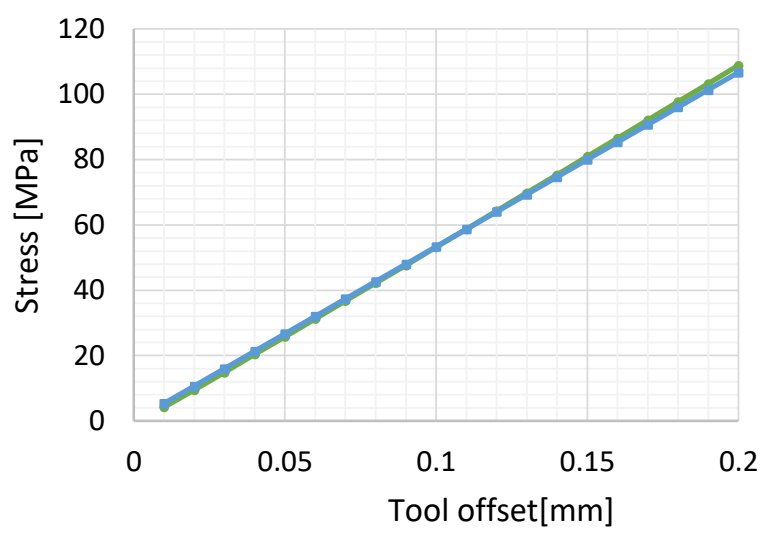

$\longrightarrow$ Experiment $\longrightarrow$ FEM analysis

Fig. 8. Stress comparison - Option 1

\section{Option 2 - Presure stress}

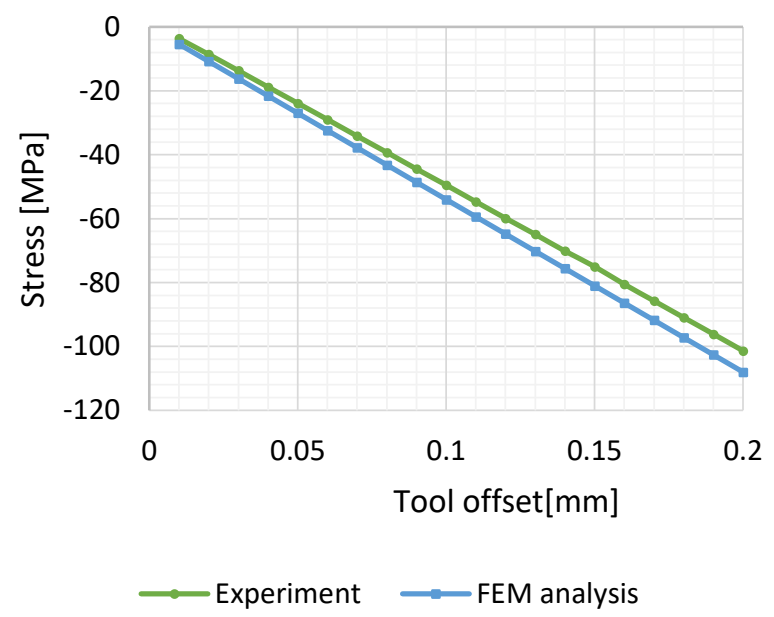

Option 2 - Tensil stress

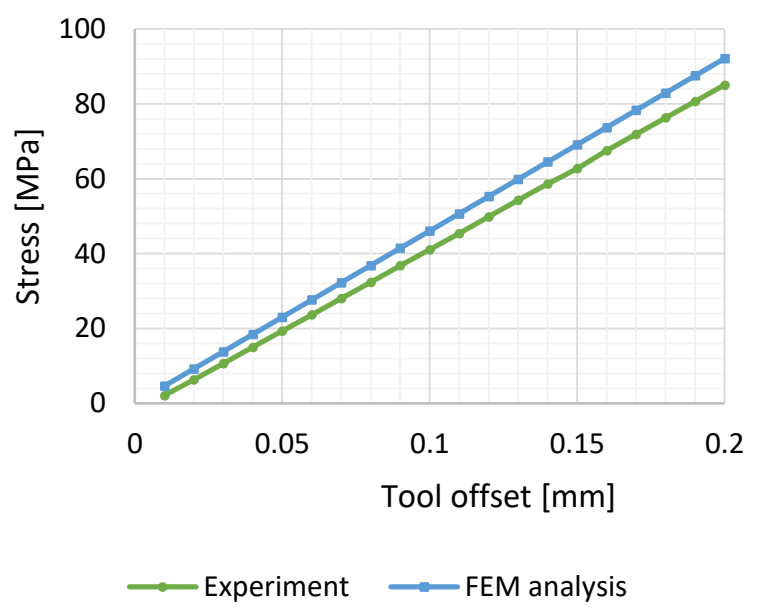

Fig. 9. Stress comparison - Option 2

The graphs in Figs. 8 and 9 compare the stresses obtained from the simulations with the stresses obtained from the strain gauges in the experiment for each offset of the tool system. The experiment showed the very small difference between the measured and calculated stress. The difference between the measured data and the calculated data is from $2 \%$ to $8 \%$. The accuracy of the simulation results increases, as does the time required for the calculation. The accuracy of the result increases with the finer meshing of the model and the increasing computing time. The results of the simulations can be considered correct and can be further used and used as a basis for further development and research of tool systems. 


\section{Conclusion}

The main aim of this paper was to verify the behaviour of tool systems loaded with static force and defined offset value using FEM analyses. For this verification were used software Autodesk Nastran In-CAD and Siemens NX 11.0. One of the main points of the work was verification of obtained data from simulations on a real prototype of the tool system. To analyse the FEM, it was first necessary to create simplified CAD tool models with different tool lengths. This was followed by a FEM analysis to determine the behaviour of the tool. And Subsequent results were shown in graphs. After performing simulations and analysis, the relevance of these results was verified on one prototype tool system. The results of FEM analyses show that the maximum stress is concentrated on the inside of the slats in the transition from the radius to the slat wall. Potential optimization of the tool system could be focused firstly on this area. Verification of FEM analyses took place in two steps. First, the simulation results were compared from another computer program, specifically Siemens NX 11.0. Already in this comparison very similar values were achieved from both simulations and the results can be considered relevant. The second step was to verify the real prototype. In both experiments the simulation was confirmed, where the results of the experiment differed on average by only 2-8\% compared to FEM analyses. Overall, the experiment confirmed the results of FEM analyses and it is therefore possible to use these analyses as starting data for further design and development of the tool system.

The indisputable advantage of verification by FEM analysis is the cost savings with respect to the real prototype experiment. In a real prototype there are costs associated with production, which will show the cost of material, machine hourly rate of the machine, the cost of operating the machine, the cost of creating CAM programs necessary for production and more. One of the big part of the cost is the experiment itself, which requires relatively expensive measuring and evaluation devices. Furthermore, the costs of professional staff are able to measure and evaluate the data. One of the main disadvantages of the experiments is their high time demands and in some cases the necessity to stop production due to experiments. The last disadvantage may be the need to measure data only at a predetermined location, as opposed to simulations where values can be obtained throughout the model.

Opportunities where these results can be used is to FEM analysis in the design of new tool centering systems, where this method of design and verification of strength is not very common. CAD models and FEM analyses are therefore perspective methods of tool system development, which can replace long, and expensive experiments based on strength testing or fatigue of these systems. Further research and development in this area will be devoted to the use of tool design using FEM analysis also in other machining methods and in tool design using 3D printing.

\section{Acknowledgments}

This article was created under the project SGS-2019-008: Research and Development for Innovation in the Field of Manufacturing Technology - Machining Technology III.

\section{References}

[1] Fiala, S; Kouril, K. \& Rehor, J. (2012). Research and development of high-precision, next generation productive cutting tools using innovative technologies and advanced materials, "in Project interim report TA02010236, Brno, HAM_FINAL s.r.o.

[2] Piska, M. \& Slany, M. (2011). On the reaming of austenitic steels with coated cermets. Annals of DAAAM for 2011 \& Proceedings of the 22nd International DAAAM Symposium, Volume 22, No. 1, ISSN 1726-9679 ISBN 978-3901509-83-4, Editor B. Katalinic, Published by DAAAM International, Vienna, Austria, EU,

[3] Fulemova, J; Kutlwaser, J; Gombar, M. \& Rehor, J. (2017). Influence of Selected Technological Factors on the Hole Quality During Reaming, Annals of DAAAM for 2017 \& Proceedings of the 25nd International DAAAM Symposium, Volume 25, No. 1, ISSN 1726-9679 ISBN 978-3-902734-11-2, Editor B. Katalinic, Published by DAAAM International, Vienna, Austria, EU,

[4] Rehor, J; Fulemova, J.; Kouril, K. \& Matous, P. (2015). Current trends of centering tools for precision hole production “. In Manufacturing Technology, Vol. 20, No. 1, pp. 48-55. ISSN: 1211-4162

[5] Smith, G. (2008) Cutting Tool Technology: Industrial Handbook, Southampton: Springer, 600 p. ISBN 1-848-00204-1., 1st edition.

[6] www.ust.fme.vutbr.cz, (2004). Humar, A., Machining technology - 2nd part. Accessed on: 2019-02-23

[7] Internal documents of company FINAL-Tools a.s. (2018)

[8] Product catalog of the company HAM-FINAL, s.r.o., Brno, (2010). 